\title{
Clinical comparison of Annabedi Chendhuram (siddha system of medicine) and elemental iron in the treatment of iron deficiency anaemia
}

\author{
R. Sivaraj ${ }^{1}$, Umarani Sivaraj ${ }^{2}$, R. Arbind Kumar Choudhary ${ }^{3, *}$, R. Abirami ${ }^{4}$ \\ ${ }^{\mathbf{1}}$ Professor and HOD, ${ }^{2,3}$ Assistant Professor, ${ }^{4}$ Staff Nurse, ${ }^{1,3}$ Dept. of Pharmacology, ${ }^{\mathbf{2}}$ Dept. of Anatomy, ${ }^{\mathbf{1}}$ Aarupadai Veedu Medical \\ College, Kirumampakkam, Puducherry, ${ }^{2}$ Rajah Murhiah Medical College \& Hospital, Annamalai University, Chidambaram, Tamil Nadu, \\ ${ }^{3}$ Perundurai Medical College, Sanatorium, Erode, Tamil Nadu, ${ }^{4}$ Valinikkom PHC, Tamil Nadu, India
}

\section{*Corresponding Author: R. Arbind Kumar Choudhary}

Email: arbindkch@gmail.com

\begin{abstract}
Introduction: Healthy human body needs iron for multiple process during development. Several diseases are associated with iron deficiency and increased demands also may lead to iron deficiency. Many diseases have been addressed by siddha system of medicine like syphilis, respiratory diseases, carcinoma etc and there has been mention of usage of metals, mineral, arsenics and hydrochemicals constituting about 220 types which are used for preparing medicines. The present study was conducted to compare the efficacy of Annabedi Chendhuram (Siddha) and Elemental iron (Allopathy) in the treatment of Iron deficiency anaemia to achieve normal function of it. Iron preparations are commonly used to improve hemoglobin content of blood. 'Vaithya Sastram' explained elaborately the diet for Pandu (anaemia).

Materials and Methods: Cross sectional multicentric Prospective randomized study is conducted in Arupadai Veedu Medical College, Kirumampakkam, Pondy to cuddalore ECR Main Road, Puducherry and IRT-Perundurai Medical College Erode, District for 45 days using two different oral iron preparation Siddha drug: Annabedi Chendhuram 100mg twice daily orally - after food. Alopathy drug.

Result and Discussion: Among the patients of group I, hemoglobin level increases 2-3 grams\% in 15 patients, 3 to 4 grams $\%$ in 7 patients, 1 gram $\%$ in 3 patients after 45 days of treatment. Among the patients of group II, hemoglobin level increases 2 grams $\%$ in 12 patients, 1 to 2 grams $\%$ in 6 patients, 1 gram \% in 2 patients after 45 days of treatment. Out of treated patients in group I, 6 patients had nausea only. Out of treated patients in group II, 2 patients had constipation only.

Conclusion: Annabedi Chendhuram (siddha) and Elemental iron (allopathy) both are equally effective but in terms of side effect siddha was slightly better further need to conduct a large sample study for better understanding
\end{abstract}

Keywords: Annabedi Chendhuram, Elemental iron, Anemia.

\section{Introduction}

Iron is required for normal vital process of the body and it manifests as deficiency either due to poor dietary supplement and increased physiological demands or failure of body to utilize the normal iron. Dietary insufficiency is most common problem in developing countries. This problem in developing countries pose a great threat to health systems and pose a challenge to health authorities. Iron deficiency not only manifests as physical problems but also cause reduction in intellectual performance. Altogether, with a high prevalence, iron deficiency has a negative impact to overall community both in terms of economic and social development. As per the World Health Organization (WHO) approximately 1.62 billion suffer from iron deficiency anemia worldwide which constitute $47 \%$ in preschool-age children, $25 \%$ in school children, $30 \%$ in non-pregnant women and $24 \%$ in people older than 60 years of age with $12 \%$ in adult men which is the least. But as a matter of fact, about 468.4 million non-pregnant women suffer from iron deficiency anemia. Geographical distribution shows, Africa and South East Asia are most affected due while Europe and the Western Pacific are least affected as per WHO data and most common factors for the cause is being infections and malnutrition. ${ }^{1}$

Dietary intake of iron rich foods is the simplest and easiest form to prevent iron deficiency anemia due to scarcity of dietary intake of iron and iron fortified food serves a greater source to replace the same as evident from many multiple studies. ${ }^{2,3}$ But the scenario of iron deficiency in developed countries are different and the cause being diseases that trigger a negative balance between iron absorption and loss where the treatment for the causative disease may eliminate the deficiency along with supplements but limitation being tolerance and low potency which may require parenteral administration of the same. Celiac disease plays a vital role in iron deficiency especially in infant and children, elderly and during pregnancy. ${ }^{4,5}$ Iron plays a very important role in metabolic process of the cell and is required for the activity of many enzymes and is a chief component of hemoglobin. However excess intake of the same also pose a great problem to the body. ${ }^{6}$ Hence iron has tight and fine regulation in the body. ${ }^{7}$ Our body does have physiological means for eliminating the excess of remaining iron and hence its slight increase also pose a threat to the body. ${ }^{8,9}$

\section{Materials and Methods}

Cross sectional multicentric Prospective randomized study is conducted in, Arupadai Veedu Medical College, Kirumampakkam, Pondy to cuddalore ECR Main Road, Puducherry and IRT-Perundurai Medical College Erode, District for 45 days using two different oral iron preparation Siddha drug: Annabedi Chendhuram 100mg twice daily orally - after food. Alopathy drug: Elemental iron 100mg once daily orally - after food, both the preparation was collected form The Indian Medical Practitioners Co- 
operative Pharmacy and Stores Limited Sales Depot Coimbatore (impcops) the outcome is compiled and compared under following headings. Improve $\mathrm{Hb}$ level, Reduce unwanted symptoms like Nausea, Altered bowel habits Ayakantha Chendhuram -Amron. The patients with following laboratory findings are taken for this study, Low serum subnormal plasma ferritin level Low $\mathrm{Hb}$ level, below 10 grams \%, Patients having low plasma ferritin level, Patients having low $\mathrm{Hb}$ (below 10 grams \%), Both male and female are included. Patients who are willingly to undergo blood investigation, Patient have to willing sing the informed consent are included. We have excluded the Patients having megaloblastic Anemia, Anemia or chronic disease, sickle - cell anaemia., Children and pregnant women Other severe illness like malignancy, liver failure, renal failure, chronic gut disease. Patient who are not willingly to undergo blood investigation. Patients who are not willing sign the informed consent are excluded.

\section{Results}

A total number of 45 patients were included for this study. Of the 45 patients 25 patients were randomized to group I, 20 to group II. 25 patients of group I were treated with Elemental iron $100 \mathrm{mg}$ once daily after food. 20 patients of group II were treated with Annabedi Chenduram $100 \mathrm{nmg}$ twice daily after food. Among the patients of group I, hemoglobin level increases 2-3 grams \% in 15 patients, 3 to 4 grams $\%$ in 7 patients, 1 gram $\%$ in 3 patients after 45 days of treatment. Among the patients of group II, hemoglobin level increases 2 grams $\%$ in 12 patients, 1 to 2 grams $\%$ in 6 patients, 1 gram $\%$ in 2 patients after 45 days of treatment. Out of treated patients in group I, 6 patients had nausea only. Out of treated patients in group II, 2 patients had constipation only.

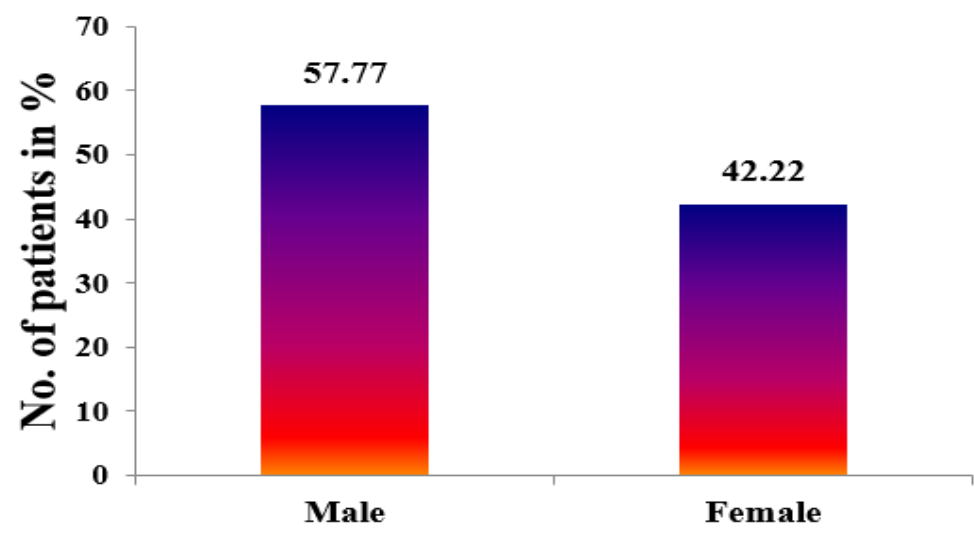

Fig. 1: Gender wise distribution of patients

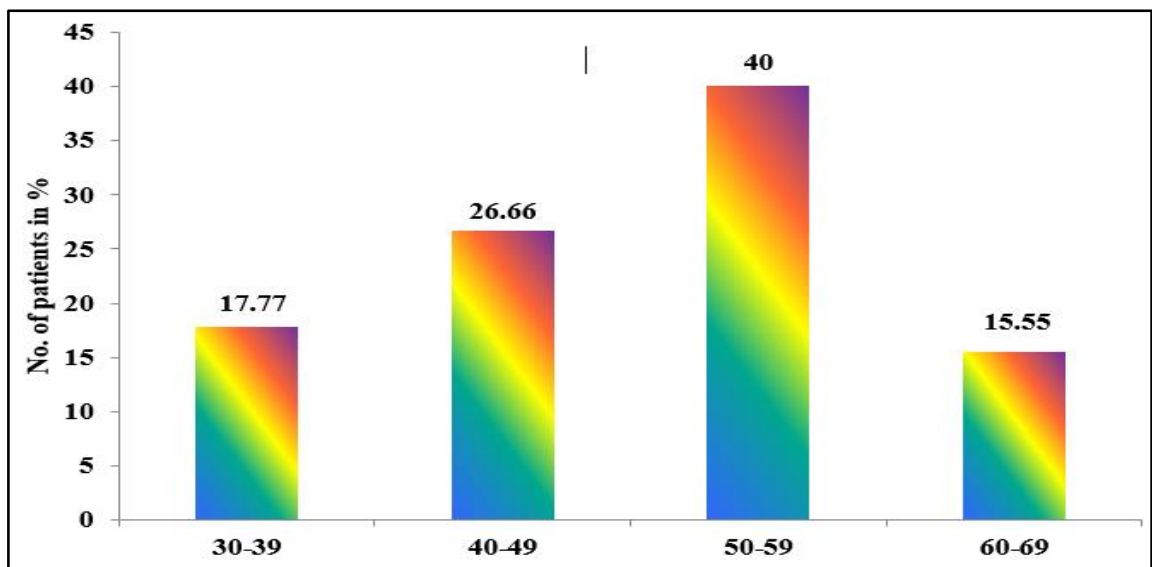

Fig. 2: Age wise distribution of patients 


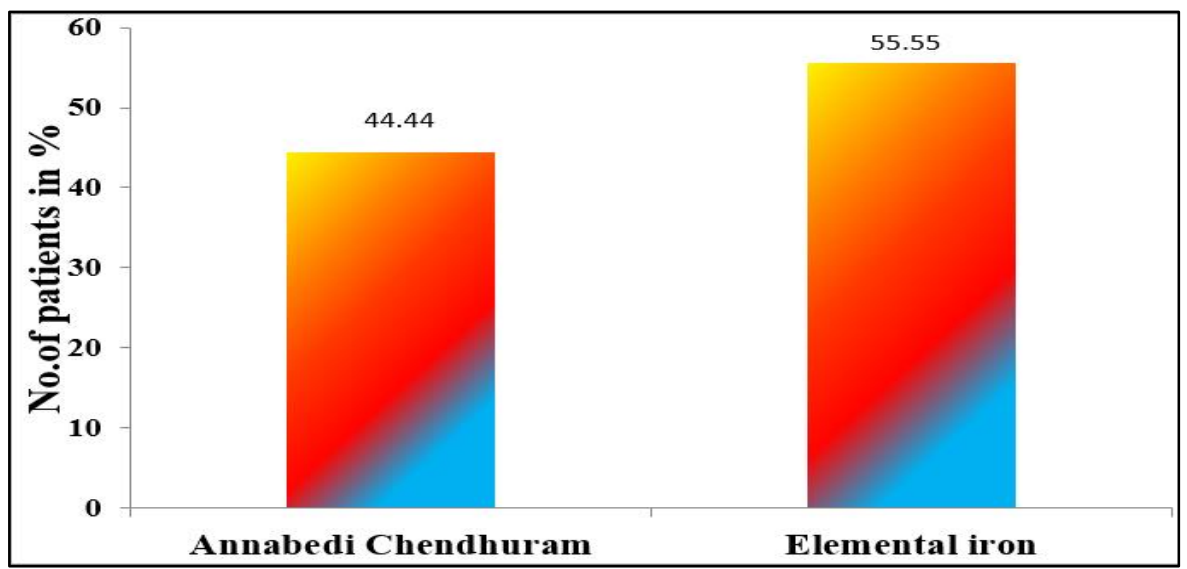

Fig. 3: Distribution of patients receiving Annabedi Chendhuram and elemental iron

Table 1: Comparison of treatments with Annabedi Chendhuram and elemental iron

\begin{tabular}{|c|c|c|c|c|}
\hline S. No & Drug & No. of Patients & $\begin{array}{c}\text { After 45 days of treatment } \\
\text { increased hemoglobin level }\end{array}$ & $\%$ \\
\hline 1 & Annabedi & $12 / 20$ & 2 grams \% & 60 \\
& Chendhuram & $6 / 20$ & $1-2$ grams \% & 30 \\
& & $2 / 20$ & 1 grams \% & 10 \\
\hline 2 & Elemental iron & $15 / 25$ & $2-3$ grams \% & 60 \\
& & $7 / 25$ & $3-4$ grams \% & 28 \\
& & $3 / 25$ & 1 grams \% & 12 \\
\hline
\end{tabular}

Table 2: Side effects profile during treatments with Annabedi Chendhuram and elemental iron

\begin{tabular}{|c|c|c|c|c|}
\hline S. No & Drug & No. of Patients & $\begin{array}{c}\text { Unwanted } \\
\text { symptoms }\end{array}$ & $\boldsymbol{\%}$ \\
\hline 1 & Annabedi Chendhuram & 20 & 2 & 10 \\
\hline 2 & Elemental iron & 25 & 6 & 24 \\
\hline
\end{tabular}

\section{Discussion}

Iron deficiency is the most common form of anaemia in worldwide, lead to decrease in the haemoglobin $(\mathrm{Hb})$ level. Decrease in the $\mathrm{Hb}$ intensity may disrupt the normal life expectancy of red blood cells synthesized in the bone marrow and liver. Siddha literature denotes that the cause for anaemia are excessive intake of salty, sour food items, toxic foods, liver disorders, bleeding piles, blood vomiting, polymenorrhagia and dysentery meanwhile allopathic system have reported same risk factor in many of scientific study. In Siddha system, Annabethi Chenthuram is prescribed as excellent medicine for anaemia where is oral iron preparation is commonly prescribe in allopathic and modern medicine. Even though this drug is commonly used for long time, till date not much comparative scientific works have been done to reveal the real impact of this drug on patient.in term of clinical efficacy, Hence, in this present work, we have determined the clinical determinant and biochemical indication and their valuable change after two group of patient prescribe iron preparation. All 45 patients were included prospective study for 45 days out. Of the 45 patients 25 patients were randomized to group I, 20 to group II. 25 patients of group I were treated with Elemental iron $100 \mathrm{mg}$ once daily after food. 20 patients of group II were treated with Annabedi Chenduram $100 \mathrm{mg}$ twice daily after food. Among the patients of group I, hemoglobin level increases $2-3$ grams $\%$ in 15 patients, 3 to 4 grams $\%$ in 7 patients, 1 gram $\%$ in 3 patients after 45 days of treatment. Among the patients of group II, hemoglobin level increases 2 grams $\%$ in 12 patients, 1 to 2 grams $\%$ in 6 patients, 1 gram $\%$ in 2 patients after 45 days of treatment. Reported adverse effect of siddha preparation was less, Out of treated patients in group I, 6 patients had nausea only. Out of treated patients in group II, 2 patients had constipation only. Both the preparation is completely safe to take this medicine in recommended doses. Effectivity of herbal medicine depends on many factors. A medicine suitable for one person may not essentially give same result in another person. Exact dose depends on the age, strength, digestive power of the patient, the nature of the illness, the state of the viscera and humours, and the properties of individual drugs. ${ }^{10}$

On higher dose Annabedi Chendhuram (siddha) and elemental iron can cause toxicity. Iron poisoning symptoms include vomiting, vomiting blood, diarrhoea, abdominal pain, irritability, low blood pressure, fast and weak pulse, shock, dehydration, fever, headache, bluish skin, and drowsiness. Depending on the severity of the overdose, the severe symptoms may occur anywhere between 12 hours and 5 weeks after taking too much iron. ${ }^{11}$ 
There must be the instruction while prescribing of Keep away from the sight and reach of children. Iron overdose is especially dangerous for children. A severe overdose can happen if a child eats iron supplements meant for adult. ${ }^{12}$

\section{Conclusion}

This study shows that for $90 \%$ of group I patients hemoglobin level increases above 2 grams $\%$ whereas in group II only $60 \%$ shows improvement. Among group I $24 \%$ of cases had unwanted symptoms. In group II only $10 \%$ of cases had unwanted symptoms. So, finally group I is slightly more effective than group II in improving hemoglobin level, but group II patients had less unwanted symptoms than group I. Annabedi Chendhuram (siddha) and Elemental iron both are equally effective but in terms of side effect siddha was slightly better further need to conduct a large sample study for better understanding.

\section{References}

1. De Benoist B, Mclean E, Egli I, Cogswell M. Worldwide Prevalence of Anaemia 1993-2005, WHO Global Database on Anemia. Geneva: World Health Organization: 2008.

2. Clark SR. Iron deficiency anemia. Nutr Clin Pract 2008;23;128888-141.

3. Mimura Ec, Bregano JW, Dichi JB, Gregorio EP Dichi I. Comparison of ferrous sulfate and ferrous glycinate chelate for the treatment of iron deficiency anemia in gastrectomized patients. Nutr 2008;24;663-668.

4. Pineda O, Ashmed Hd. Effectiveness of treatment of iron deficiency anemia in infants and yound children with ferrous bis-glycinate chelate. Nutr 2001;17:381-384.

5. Fishbane S, Kowalski EA. The comparative safety of intravenous iron dextran, iron saccharate, and sodium ferric gluconate. Semin Dial 2000;13(6):381-384.
6. Yip R, Schwartz S, Deinard AS. Screening for iron deficiency with the erythrocyte protoporphyrin test. Pediatr 1983;72;214219.

7. Thyagarajan R. Gunapadam Thaathu Jeeva Vaguppu, 4th ed. Chennai: Department of Indian Medicine and Homeopathy; 2004.

8. Ganguli MN, Singh RK, Jamadaghi SB, Mitra A, Upadhyay SN, Hazra J. Toxicological evaluation of kasisabhasma, an Ayurvedic organa metallic preparation. Int J Res Ayurveda Pharm 2012;3:381-386.

9. Anonymous. The Siddha Formulary of India. New Delhi: Ministry of Health and Family Welfare, Department of AYUSH, Government of India; 1992.

10. Nishakumari PR, Dinesh Nayak J, Sathyanarayana B. Comparative antimicrobial study of shuddha Kasisa and Kasisa Bhasma. Int Ayur Med J 2016;4:579-583.

11. Palbag S, Saha D, Gautam DNS. Toxicity studies of ironcontaining Ayurvedic drug Kasisa Bhasma. BLDE Univ J Health Sci 2016;1:39-43.

12. Anonymous. Pharmacopoeial Standards for Ayurvedic Formulations. New Delhi: Central Council for Research in Ayurveda and Siddha, Ministry of Health and Family Welfare; 1987.

How to cite this article: Sivaraj R, Sivaraj U, Choudhary RAK, Abirami R. Clinical comparison of Annabedi Chendhuram (siddha system of medicine) and elemental iron in the treatment of iron deficiency anaemia. Int $\mathbf{J}$ Comprehensive Adv Pharmacol 2018;3(4):142-145. 